Research Article

\title{
A Modified Newmark Method for Calculating Permanent Displacement of Seismic Slope considering Dynamic Critical Acceleration
}

\author{
Yulong Cui $\mathbb{D}^{1},{ }^{1}$ Aijuan Liu, ${ }^{2}$ Chong Xu $\mathbb{D}^{3,4}$ and Jun Zheng ${ }^{5}$ \\ ${ }^{1}$ School of Civil Engineering and Architecture, Anhui University of Science and Technology, Huainan 232001, China \\ ${ }^{2}$ China Three Gorges Corporation, Beijing 100038, China \\ ${ }^{3}$ Institute of Crustal Dynamics, China Earthquake Administration, Beijing 100085, China \\ ${ }^{4}$ Key Laboratory of Active Tectonics and Volcano, Institute of Geology, China Earthquake Administration, \\ Beijing 100029, China \\ ${ }^{5}$ Department of Civil Engineering, Zhejiang University, Hangzhou 310058, China
}

Correspondence should be addressed to Yulong Cui; ylcui@aust.edu.cn

Received 22 March 2019; Revised 14 June 2019; Accepted 10 July 2019; Published 15 September 2019

Academic Editor: Giovanni Biondi

Copyright (c) 2019 Yulong Cui et al. This is an open access article distributed under the Creative Commons Attribution License, which permits unrestricted use, distribution, and reproduction in any medium, provided the original work is properly cited.

Newmark permanent displacement is an important index for evaluating seismic slope stability, which has been widely used in recent years. The traditional Newmark sliding method assumes that the critical acceleration is constant but does not consider the inhomogeneity and dynamic reduction process of shear strength on the sliding surface, presumably leading to underestimation of the permanent displacement. In this paper, this problem is analyzed, and a new method for calculating permanent displacement of seismic slope considering dynamic critical acceleration is proposed, in which the Monte Carlo simulation is used. Example calculations indicate that this approach permits to show the dropping cohesion and the dynamic critical acceleration of the slide block during the earthquake time history. The improved method for calculating seismic slope permanent displacement presented in this paper solves the problem that the calculated value from the Newmark sliding method is smaller than the real value and is a useful improvement.

\section{Introduction}

In recent years, dozens of large earthquakes with magnitude greater than $M 7.0$ have occurred worldwide [1-5], which directly caused huge losses of lives and property, and induced secondary effects such as tsunamis and landslides, greatly aggravating the degree of disasters. For example, the 2008 Wenchuan, China, M 7.9 earthquake triggered more than 56,000 landslides, killing about 20,000 people accounting for one-fourth of the total deaths [6].

Many researchers have studied the distribution of these earthquake-induced landslides [7-9]. Meanwhile, other studies focused on hazard assessment in the areas for the site selection of major projects and resettlement of migrants in mountainous areas where no major earthquakes happened so far but are with potential seismic risk in the future. In this aspect, the seismic slope stability analysis and evaluation method is a piece of basic work.

The Newmark sliding method was proposed by Newmark [10], which considers that the slide will begin to slip when the seismic acceleration exceeds the critical acceleration, and the final displacement of the slide can be obtained by double integral over the time of the difference between the seismic acceleration and the critical acceleration, which is called permanent displacement. The calculated permanent displacement can be used to judge whether the slide block will be unstable during an earthquake, and Wieczorek [11] suggested its value of $5 \mathrm{~cm}$. Based on the Newmark sliding method, many scholars have studied the permanent displacement of slopes under various conditions, such as single-slide failure [12, 13], multiple-slide 
failure [14], wedge failure [15], and circular sliding [16]. At the same time, different methods, e.g., the energy conservation principle [17], three-dimensional space analysis theory [18], and finite element time-history analysis [19], have been used to analyze the permanent displacement of seismic slopes. Both the original Newmark sliding method and these improved tools assume that the shear strength of rock-soil body remains unchanged during an earthquake, so the critical acceleration of the slope also remains unchanged. But in fact, the shear strength on the potential slide surface decreases gradually during earthquake time history $[10,20,21]$, and the critical acceleration will also change. Newmark [10] himself had realized that constant shear strength and critical acceleration are unreasonable, and he suggested that the change of shear strength and critical acceleration should be taken into account when calculating permanent displacement with the Newmark method. Regretfully, this recommendation has not been taken seriously and applied by subsequent users. Shaking-table tests show that the permanent displacement obtained by considering the change of soil strength during the shaking process is more consistent with the relevant experiment results [22]. For this reason, Bandini et al. [23] derived the formula for calculating the permanent displacement of a slope with consideration of the attenuation of soil strength and the geometric deformation of strips in the slope vibration deformation course and compared it with those of shaking table tests, which verified the rationality of the formula. Li et al. [24] calculated the postearthquake displacement of a dam slope with the Newmark sliding method considering the change of soil strength during earthquake time history. Chen and Xia [25] have conducted theoretical deduction and program compilation and iterated and updated the strength of rock and soil in real-time, which permits to fully consider the dynamic change of critical acceleration in the process of the slide deformation. And they applied the dynamic critical acceleration to the Newmark sliding method and obtained the time-history curve of slope displacement which employed the dynamic strength of sliding surface under seismic action. Although the above improved methods have considered the dynamic change process of rock and soil strength during an earthquake, most of them do not take the inhomogeneity of shear strength on the slide surface into account synchronously; thus, the permanent displacement would be underestimated, which is not consistent with the real situation.

Therefore, combining with the inhomogeneity theory of shear strength in rock-soil bodies, this paper presents a modified Newmark method which simulates the dynamic reduction of critical acceleration and calculates the permanent displacement. In this method, the cohesion of different particles on the potential slide surface is assumed as a certain probability distribution and is simulated by the Monte Carlo method, so each particle will have an individual critical acceleration. In the course of seismic action, the particle whose critical acceleration exceeds the seismic acceleration will lose its cohesion; thus, the total cohesion and the total critical acceleration of the potential slide surface will gradually decrease during the earthquake time history. Taking a seismic wave time-history curve as an example, it is found that this method can calculate a permanent displacement which is closer to the reality. The results indicate that this method has good applicability and can be further developed as an effective supplement to the Newmark sliding method.

\section{Theory and Method}

2.1. Theoretical Analysis. In the Newmark sliding method, the slide block of the slope is simplified as a rigid block on the slope plane, under the action of seismic force, the block will slide and the displacement accumulates along the sliding surface. The permanent displacement of the slide block during the earthquake can be obtained by double integral over the time of the difference between the seismic acceleration and the critical acceleration. The formula for calculating critical acceleration in the horizontal direction [26], which ignores the effect of water, is

$$
a_{\mathrm{c}}=\left(\frac{c}{\gamma t \sin \alpha}+\frac{\tan \varphi}{\tan \alpha}-1\right) \frac{\tan \alpha}{(\tan \varphi \tan \alpha+1)} \cdot g,
$$

where $c$ is the total cohesion at the bottom at a certain time; $\varphi$ is the internal friction angle on the slide surface; $\gamma$ is the weight of the slide block; $t$ is the depth of potential slide surface (perpendicular to the slide surface); $\alpha$ is the dip angle of the slide surface; and $g$ is the gravity acceleration.

In the basic theory of shear effect in geomechanics, cohesion and internal friction angle are two basic parameters of shear strength, no matter the slope is rock mass or soil mass. It remains difficult to determine the cohesion and internal friction angle changing process under the special earthquake force. According to the definition of cohesion, it is mainly formed by the long-term geological process of rock and soil. Once the slide surface is formed during the shearing process, the slide body is separated from the slide bed; then, the cohesion is considered to be destroyed and lost. So far, there is no instrument available to measure the internal friction angle in the seismic time history. But it is certain that the effect of internal friction angle in rock and soil is different from that in classical physical mechanics. Friction in classical mechanics originates from the interface between two objects, and there is only a hypothetical potential sliding surface before the slope slides, and friction in classical physical mechanics occurs only when the slide surface is fully connected. Therefore, the internal friction angle is regarded as an internal parameter of the slope body before the slide surface is completely holingthrough, and its essence is the friction between particles. Then, the internal friction angle will keep producing the shear effect before the slide surface penetrated.

In nature, the distribution of cohesion at the bottom of the slide block is inhomogeneous. Lumb [27], Luo et al. [28], and Yang et al. [29] carried out the experimental analysis of shear strength of rock and soil in the slope, respectively. They found that the shear strength conforms to normal distribution, lognormal distribution, and some other probability distribution types. In the Newmark sliding method, the landslide is regarded as a slide block, and the distribution of shear strength on the whole slide surface should satisfy a certain probability distribution. 
According to the above theoretical analyses, the bottom of the slide block can be fragmented into many particles with different cohesions that conform to a certain probability distribution. According to the average and standard deviation of the cohesion, cohesion of all particles is randomly simulated using the Monte Carlo method. Simultaneously, all particles will produce an independent critical acceleration. In the earthquake action process, the seismic acceleration and critical acceleration of each particle are compared at any time. If the critical acceleration of a particle is exceeded by the seismic acceleration, it is considered destroyed and its bottom surface breaks away from the slide bed; then, the particle loses its critical acceleration and withdraws from shearing work. Since then, the acceleration of the slide begins to cut down; it is only contributed by the particles whose critical acceleration is not exceeded by the seismic acceleration. The critical acceleration of the slide at any time could be calculated and plotted, based on which the permanent displacement could be calculated. When the critical acceleration of all particles is exceeded by the seismic acceleration, then the slide surface is considered been penetrated completely.

The whole process above is exhibited in Figure 1. Figure 1(a) shows a schematic of the slide block and the slide bed; $m$ particles in Figure 1(b) possess $m$ different critical acceleration at t0. Figure 1(c) shows $n$ particles whose critical acceleration is exceeded by the seismic acceleration at $t 1$, their bottom surface breaks away from the slide bed and their critical acceleration is lost. Figure 1(d) shows all the particles have lost their critical acceleration at $t 2$, the bottom of the slide block is completely penetrated, and the cohesion and internal friction angle will no longer play any role.

2.2. Monte Carlo Simulation. According to the above principles, the dynamic process of the critical acceleration on the bottom surface is simulated by the MATLAB program, and the permanent displacement is also calculated. The cohesion random number at the bottom can be generated by the Monte Carlo method. In the simulation process, if the simulation number is enough, the calculation accuracy can be relatively high. The Monte Carlo method is known as a statistical experiment method or random simulation method, which is a mathematical tool to simulate sampling values with a certain distribution of random variables and can solve the operation problem of random variables [30]. The specific implementation steps are as follows:

(i) According to the probability distribution of cohesion, $m$ particles with different cohesion are generated by the Monte Carlo method.

(ii) Calculate the corresponding critical acceleration of the $m$ particles according their cohesion.

(iii) Read in the seismic acceleration time-history curve to determine the number of the particles $(n)$ whose critical acceleration are exceeded by the seismic accelerations at each seismic moment. (iv) Remaining critical acceleration at this moment is calculated by formula (2):

$$
a_{c}(i)=\frac{\left(\sum_{j=1}^{m} a_{c p}-\sum_{j=1}^{n} a_{c p}\right)}{m} .
$$

In which $a_{c(i)}$ is the critical acceleration of the slide block in $i$ moment, with a unit of $g$; $a_{c p}$ is the critical acceleration on the bottom of the slide block particle in $i$ moment, with a unit of $g$.

(v) The critical acceleration of the slide block at any time could be calculated in step iv; then, it is drawn in coordinate diagrams with time $t$ as the transverse axis, which show the gradually decreasing and dynamic critical acceleration.

(vi) The difference between seismic acceleration and dynamic critical acceleration is calculated, and the velocity and permanent displacement is obtained with integral calculation over time.

(vii) Transform the value of the velocity and permanent displacement from horizontal direction to the sliding direction.

Because the cohesion of each particle generated by the Monte Carlo method is random every time, despite the same seismic wave time-history curve, the same slope parameters, and the same probability distribution and standard deviation, the calculated permanent displacements of each time are still different, so the average permanent displacement of 40 times calculation is used for analysis.

When the average permanent displacement of 40 times calculation for different cohesion random numbers tends to be stable, the cohesion random number is thought to be reasonable and could be used. An example (Figure 2) shows that the fluctuation of average permanent displacement weakens rapidly when the random number exceeds 200 . So, 1000 is enough to be the cohesion random numbers; that means each calculation consists of 1000 particles, which is also in accordance with the thoughts of the random number in the Monte Carlo method.

2.3. Probability Distribution Types and Standard Deviation of Shear Strength. The probability distribution type of shear strength should be determined by real measured data, and such measured data available are primarily from the analysis of a certain project site, while the measured data on the bottom of a slide which can directly conform the distribution characteristics of shear strength in the Newmark sliding method is largely absent at present. The proposed distribution types of shear strength include normal distribution and lognormal distribution $[27,29,31]$, extreme-value I distribution and Weibull distribution [32], and Beta distribution [27]. These research results indicate that the shear strength can accept various distribution types. The reason for this is that, on 


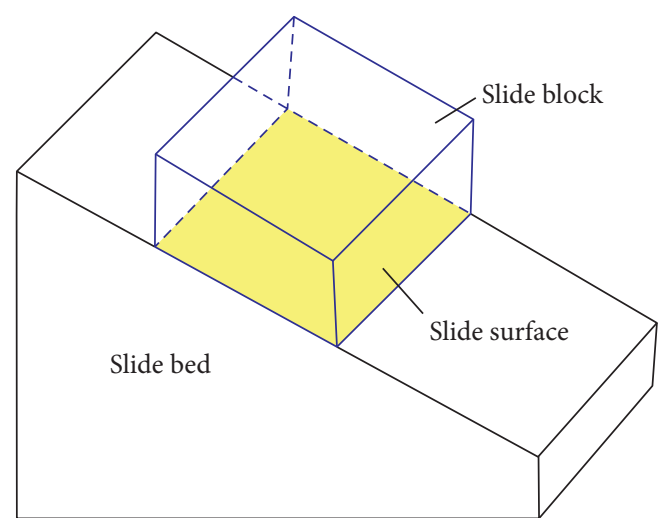

(a)

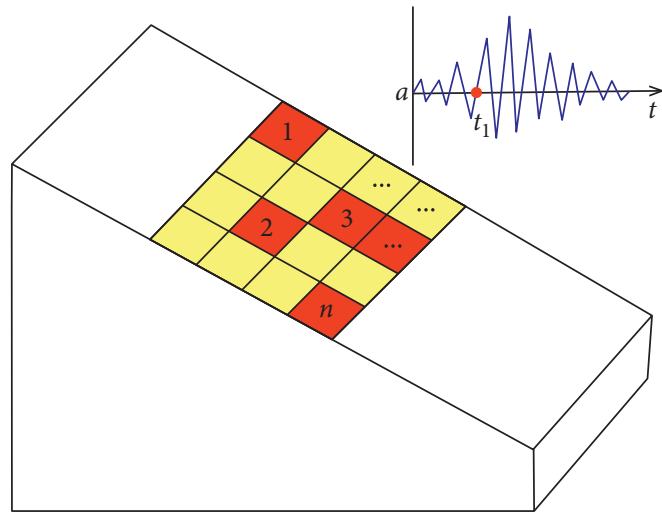

(c)

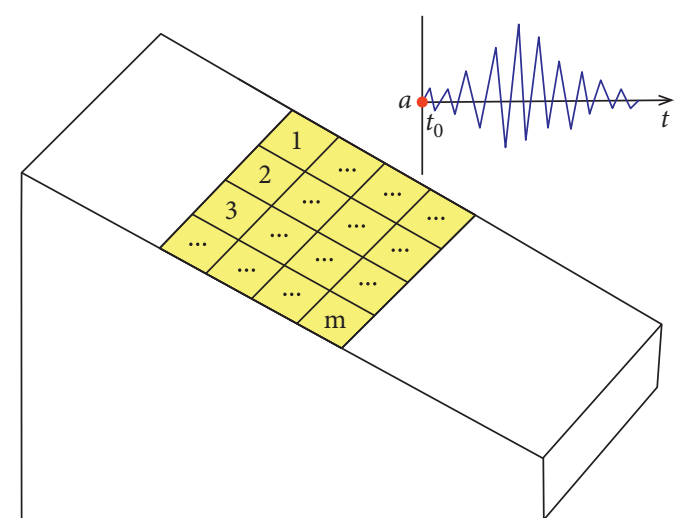

(b)

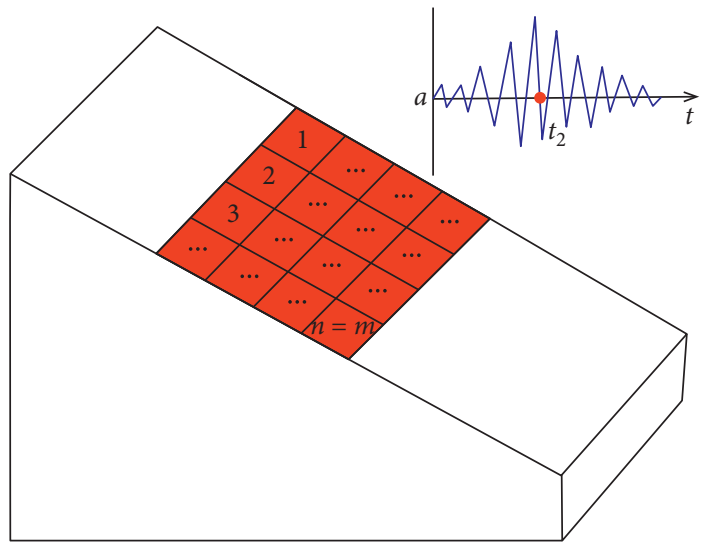

(d)

FIGURE 1: Schematic diagrams of the simulated sliding block's failure process. Yellow particles hold cohesion while the red particles have lost cohesion.

one hand, a small number of samples would lead to the acceptance of various distribution types and on the other hand, different scholars' habits and preferences would also affect the corresponding results. Through detailed analysis of the characteristics of geotechnical parameters, Zhang and Miao [33] found that the normal distribution and lognormal distribution are more suitable for shear strength of rock-soil body and other distributions are relatively not suitable.

No matter normal distribution or lognormal distribution, it is necessary to determine the standard deviation of shear strength. When determining the standard deviation, the scope of the slope should be considered when the slide occurs. The bottom surface of the slide block in the Newmark sliding method can be regarded as the potential slide surface of each slope, so the distribution range of cohesion is the whole potential slide surface of the slope. The cohesion standard deviation should not be too large or too small and should reflect the dispersion of cohesion within the scale of slope. If the standard deviation is too large, the cohesion of the slide will be too scattered, which is different from the real situation and will make the permanent displacement difference of the same seismic time-history curve too large, which is not conducive to the decision-making of the permanent displacement. If the standard deviation is too

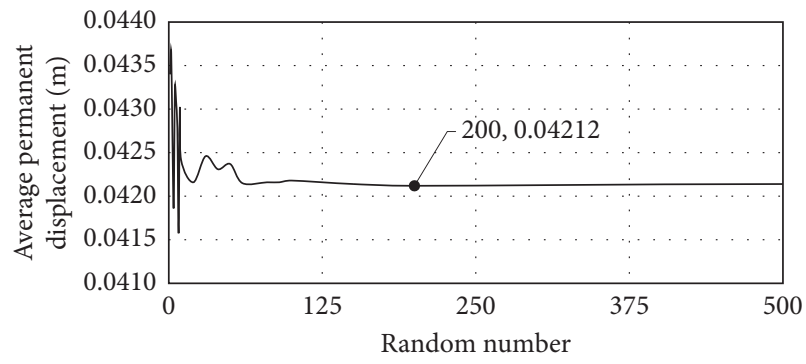

FIGURE 2: Relation between the cohesion random number and the average permanent displacement.

small, it cannot reflect the discreteness of cohesion, and there is little difference. And then the calculation process and results cannot reflect the dropping of cohesion and critical acceleration.

Generally speaking, the shear strength standard deviation should be obtained from experimental data. If such experimental data is absent, other similar data and commonly used data should be consulted. Some studies have given test data in this aspect. For instance, Gui et al. [34] gave the cohesion standard deviation for fully weathered granite to be $4.35 \mathrm{kPa}$. Cheng et al. [35] offered the standard deviation of two groups of slide zone soil of the Qianjiangping 
landslide to be $2.96 \mathrm{kPa}$ and $1.73 \mathrm{kPa}$, respectively. Xia and Jiang [36] used a random fuzzy method to calculate the cohesion standard deviation of a landslide in China to be $6 \mathrm{kPa}$. Yin et al. [37] gave the cohesion standard deviation of Tianjin soft soil to be $8 \mathrm{kPa}$. Li et al. [38] measured the cohesion standard deviation of a landslide slip zone to be $2.37 \mathrm{kPa}$ by laboratory geotechnical tests. And when selecting the shear strength standard deviation for simulating earthquake landslide, Wang et al. [39] assumed that the cohesion conforms to normal distribution with a standard deviation of $5 \mathrm{kPa}$.

\section{Results and Analysis}

3.1. Probability Distribution Form. In order to determine which probability distribution type and which standard deviation are more suitable for the distribution characteristics of shear strength and can be applied to the calculation of permanent displacement, three seismic wave time-history curves of the Chichi, Taiwan, earthquake from Pacific Earthquake Engineering Research Center [5] are selected to calculate the permanent displacement (Figure 3). When calculating each curve, it is assumed that the cohesion conforms to lognormal distribution and normal distribution, respectively. Each curve is calculated 40 times, and their average value is analyzed. The slope parameters are set as follows: slider thickness $5 \mathrm{~m}$, slope angle $20^{\circ}$, unit weight $21 \mathrm{kN} / \mathrm{m}^{3}$, internal friction angle $30^{\circ}$, and average cohesion $30 \mathrm{kPa}$. In the calculation process, the cohesion standard deviation is adopted if the cohesion is normal distribution, and the logarithm of cohesion standard deviation was adopted if the cohesion is lognormal distribution. The calculation results are shown in Table 1 and Figure 4.

Figures 4(a) and 4(b) indicate the permanent displacement is decreasing with the increasing of cohesion standard deviations and reduces to zero ultimately. This is because the bigger the standard deviation, the stronger the discreteness of the critical acceleration for each particle; then, the critical acceleration of some particles is always not exceeded by the seismic acceleration, which leads to the permanent displacement zero. When the cohesion standard deviation is very small, the critical acceleration of the particles has weaker discreteness and the calculation result of permanent displacement will get ever closer to that of the traditional calculation method (Newmark sliding method).

Figures 4(c) and 4(d) indicate when the cohesion standard deviations take the median value, the permanent displacement standard deviation has the maximum value and gradually decrease to both sides. The median value indicates the cohesion has appropriate discreteness, which mean the cohesion generated at random varies each time, but the distribution is appropriate. This lead 40 times of calculation results has certain discreteness, so the permanent displacement maximal standard deviation is the maximum value. In the left side, the cohesion standard deviation is getting smaller and the discreteness of critical acceleration is also getting smaller; when it reduces to certain degree, each particle has the same value, and this will equivalent to the traditional calculation method. In the right side, the cohesion standard deviation is getting bigger, the discreteness of cohesion and critical acceleration will be too big, and the critical acceleration of many particles will exceed the seismic acceleration, which will lead the permanent displacement tend to zero and a minor standard deviation.

When comparing Figures $4(a)-4(d)$, it could be found that no matter the normal distribution or the lognormal distribution, the permanent displacement and its standard deviation all show similar changing rules. So, when choosing the probability distribution type of cohesion, normal distribution with more convenient calculation and easier measurement of standard deviation is suggested. Which values of cohesion standard deviation are more conducive to the realization of dynamic reduction of critical acceleration is relevant to slope parameters and the seismic acceleration time-history curve. When choosing it, more attention should be paid to the actual distribution type of slope cohesion, and the above trial calculation results can be referred to appropriately.

\subsection{Calculation Results of the Permanent Displacement.} Then a seismic acceleration time-history curve (Figure 5) of the 1999 Chichi earthquake [5] with peak acceleration of $0.6918 \mathrm{~g}$ selected for calculation. The dynamic critical acceleration and invariant critical acceleration are used, respectively, to calculate the permanent displacement of this seismic acceleration time-history curve. The assumed material parameters of slope are $40 \mathrm{kPa}$ for average cohesion, $35^{\circ}$ for internal friction angle, $21 \mathrm{kN} / \mathrm{m}^{3}$ for unit weight, $30^{\circ}$ for slope angle, and $5 \mathrm{~m}$ for slider thickness. The cohesion obeys normal distribution and the standard deviation is selected as $3 \mathrm{kPa}$. Then, the permanent displacement is calculated by the MATLAB program.

The critical acceleration curve, calculated velocity curve, and permanent displacement curve are shown in Figures 5 and 6, respectively. The critical acceleration in Figure 5 is a straight line and remain unchanged while the critical acceleration in Figure 6 is dynamic and decreasing. When the critical acceleration of all particles does not work, it reduces to zero from initial value of $0.4007 \mathrm{~g}$. The displacement curves in Figures 5 and 6 show the permanent displacement increase significantly from $0.0011 \mathrm{~m}$ to $0.0421 \mathrm{~m}$.

The calculated permanent displacement with dynamic critical acceleration is bigger than that with constant critical acceleration. This does not mean that the slider must reach such a calculated permanent displacement in the real situation, instead it is because the slope surface is assumed to be infinitely long, so the displacement occurs continuously throughout the earthquake time history, resulting in a great value. In practice, the slope surface has a specific length rather than an infinite length. When the slide reaches a position, even if the earthquake has not ended, the slide block will gradually stop. However, it is not clear at which time the slide block will stop sliding, and it is impossible to define the permanent displacement at some point in the earthquake time history. Despite the above theoretical 


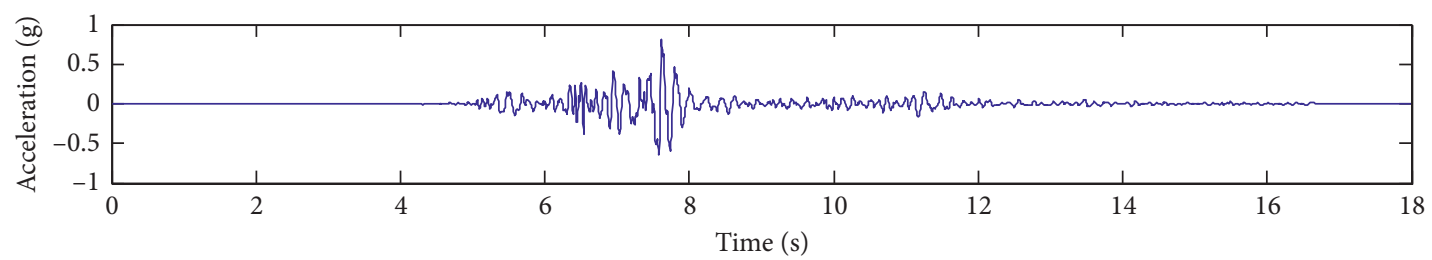

- Curve 1

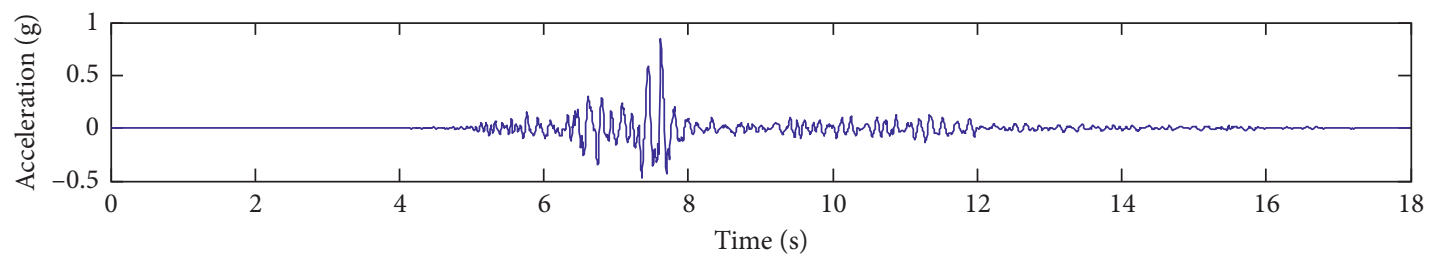

- Curve 2

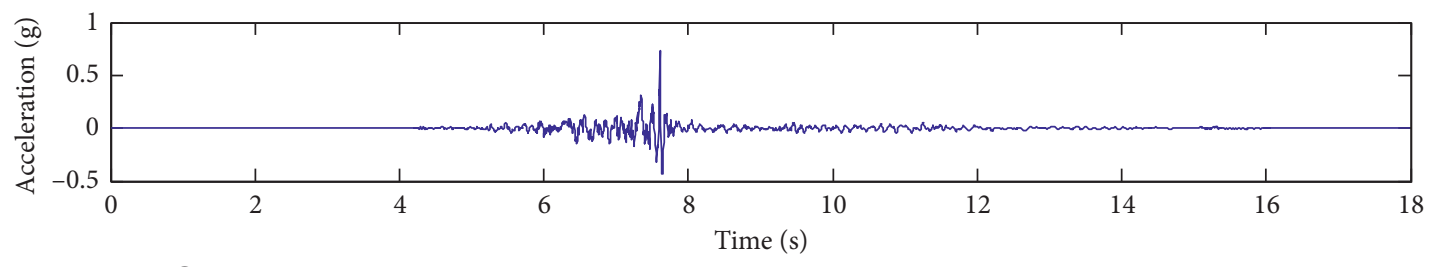

- Curve 3

FIgURE 3: Three seismic acceleration time-history curves of Chichi, Taiwan, earthquake.

TABLe 1: Calculation results of the permanent displacement for seismic time-history curves 1, 2, and 3.

\begin{tabular}{|c|c|c|c|c|c|c|}
\hline Curve & $\begin{array}{c}\text { Cohesion } \\
\text { standard } \\
\text { deviation }(\mathrm{kPa})\end{array}$ & $\begin{array}{c}\text { Average } \\
\text { permanent } \\
\text { displacement }(\mathrm{m})\end{array}$ & $\begin{array}{l}\text { Permanent displacement } \\
\text { standard deviation }(\mathrm{m})\end{array}$ & $\begin{array}{c}\text { Logarithm of } \\
\text { cohesion standard } \\
\text { deviation }\end{array}$ & $\begin{array}{c}\text { Average } \\
\text { permanent } \\
\text { displacement }(\mathrm{m})\end{array}$ & $\begin{array}{c}\text { Permanent } \\
\text { displacement } \\
\text { standard } \\
\text { deviation }(\mathrm{m})\end{array}$ \\
\hline \multirow{5}{*}{ Curve 1} & 10 & 0.06902 & 0.00019 & 0.05 & 0.06859 & 0.000049 \\
\hline & 16 & 0.06522 & 0.002016 & 0.1 & 0.06876 & 0.000113 \\
\hline & 20 & 0.05387 & 0.003599 & 0.2 & 0.04444 & 0.003848 \\
\hline & 25 & 0.03878 & 0.002127 & 0.3 & 0.02115 & 0.001312 \\
\hline & 35 & 0.02133 & 0.001257 & 0.4 & 0.01077 & 0.001049 \\
\hline \multirow{5}{*}{ Curve 2} & 16 & 0.05998 & 0.001347 & 0.1 & 0.06369 & 0.000333 \\
\hline & 20 & 0.04958 & 0.003669 & 0.2 & 0.03909 & 0.003272 \\
\hline & 25 & 0.03327 & 0.003259 & 0.3 & 0.01689 & 0.000939 \\
\hline & 30 & 0.02271 & 0.00167 & 0.4 & 0.01041 & 0.000766 \\
\hline & 35 & 0.01721 & 0.001088 & 0.6 & 0.00115 & 0.000483 \\
\hline \multirow{5}{*}{ Curve 3} & 9 & 0.01962 & 0.00139 & 0.05 & 0.0203 & $1.054 \times 10^{-17}$ \\
\hline & 14 & 0.0115 & 0.001859 & 0.1 & 0.01925 & 0.001625 \\
\hline & 16 & 0.00721 & 0.001716 & 0.15 & 0.0076 & 0.001856 \\
\hline & 20 & 0.00214 & 0.000543 & 0.2 & 0.00162 & 0.000309 \\
\hline & 22 & 0.00135 & 0.000232 & 0.25 & 0.00081 & 0.000041 \\
\hline
\end{tabular}

limitations, the magnitude of permanent displacement in the improved method can be used to characterize the displacement of different earthquake slopes and further to evaluate the relative risk.

In order to understand the value of the permanent displacement when the cohesion is zero, the cohesion is set to zero and the other parameters keep unchanged. The calculation result in Figure 7 indicates the critical acceleration is constant with a value of $0.0875 \mathrm{~g}$. This value is only contributed by internal friction angle, so it is smaller than the original critical acceleration. Because of the smaller critical acceleration, the permanent displacement of $0.01362 \mathrm{~m}$ is far bigger than the original value of $0.0011 \mathrm{~m}$. The calculation results further illustrate that the critical acceleration of a slope represent its resistance to earthquake, and the resistance is contributed by the cohesion and internal friction angle.

\section{Discussion}

Many studies have confirmed that the Newmark permanent displacement is less than the real displacement of the slide 


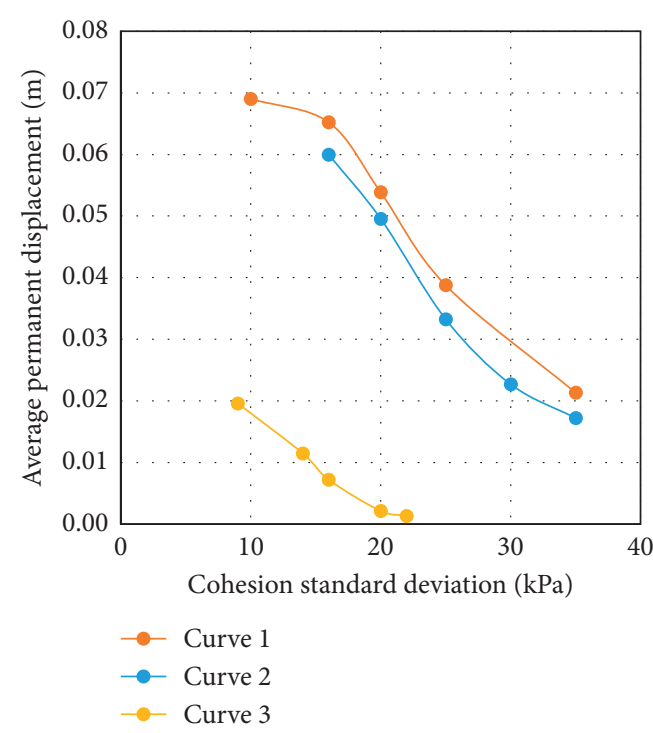

(a)

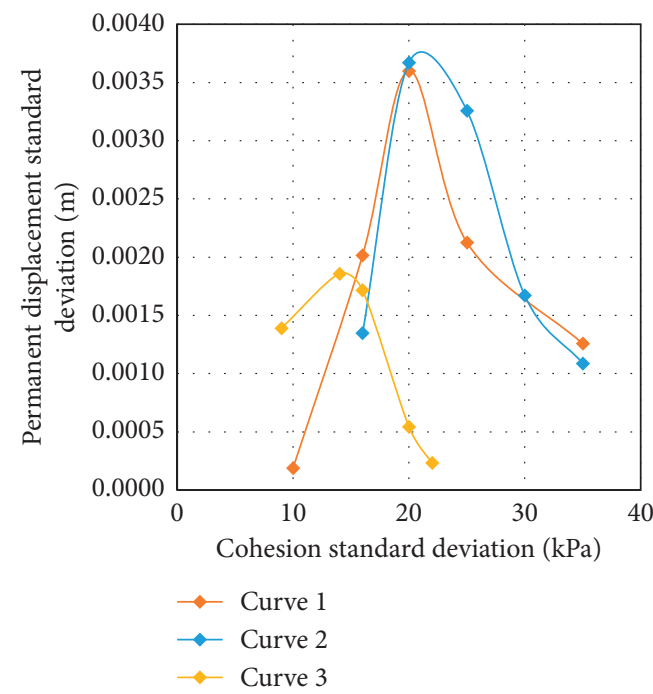

(c)

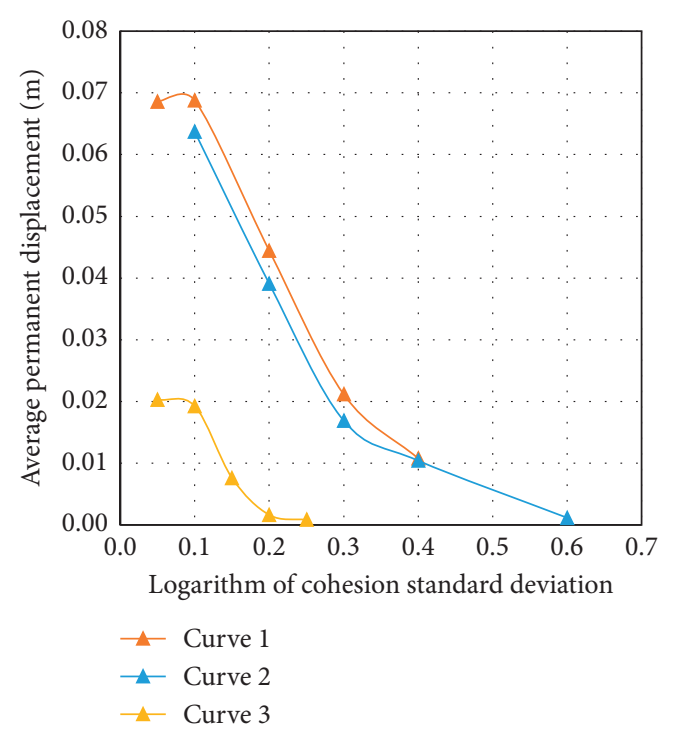

(b)

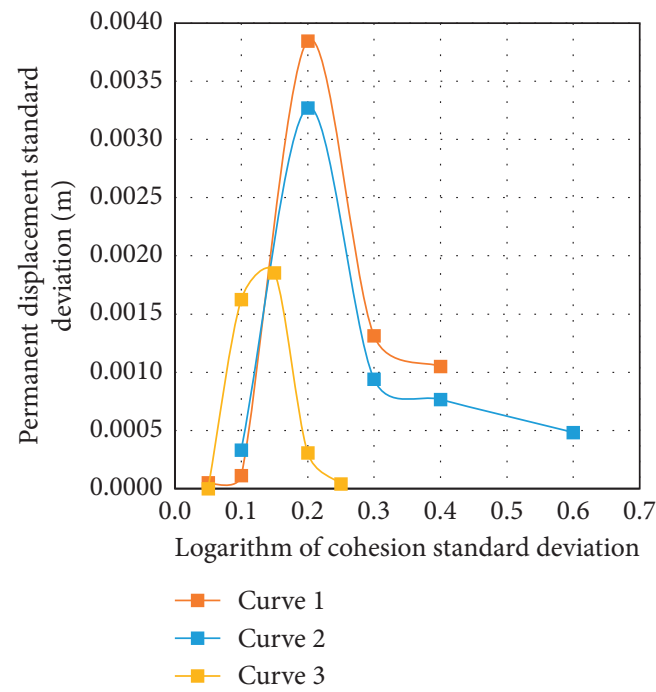

(d)

Figure 4: (a) Average permanent displacement under normal distribution, (b) average permanent displacement under lognormal distribution, (c) permanent displacement standard deviation under normal distribution, and (d) permanent displacement standard deviation under lognormal distribution.

block. For example, Meehan and Vahedifard [40] compared the postearthquake displacement observations of 122 dams and dikes with the prediction values from 15 kinds of Newmark displacement algorithms. The results show that all the predicted displacements are smaller than the real values observed, with differences more than $1 \mathrm{~m}$. Then, they suggested that the designers should pay attention to the difference between predicted and real values when using the Newmark sliding method.

The actual monitoring slip displacement of seismic slide block is very scarce. Because earthquakes are random, and the location of seismic slide block is also difficult to ascertain. So, it is impossible to set up instrument to monitor the slip displacement of slide block.
In addition, 130 seismic time-history curves are selected, and the corresponding slope parameters are set for calculation. Comparison of two permanent displacements calculated by dynamic critical acceleration and nondynamic critical acceleration indicates that the former is about $96 \%$ larger than the latter. For a single slope, the increase of permanent displacement is related to the contribution of cohesion to the critical acceleration and seismic acceleration waveforms. Even with the same peak acceleration, with different waveforms and peak times, different permanent displacements will be produced.

Although the improved method presented in this paper can reflect the shear strength reduction process of the slider bottom to a certain extent, the shear strength decreases a little fast. The reason is that only the cohesion 


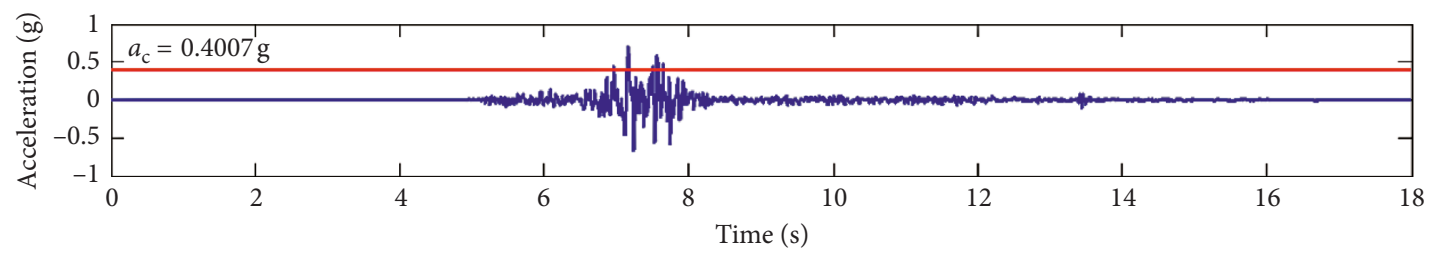

The seismic acceleration

- The critical acceleration
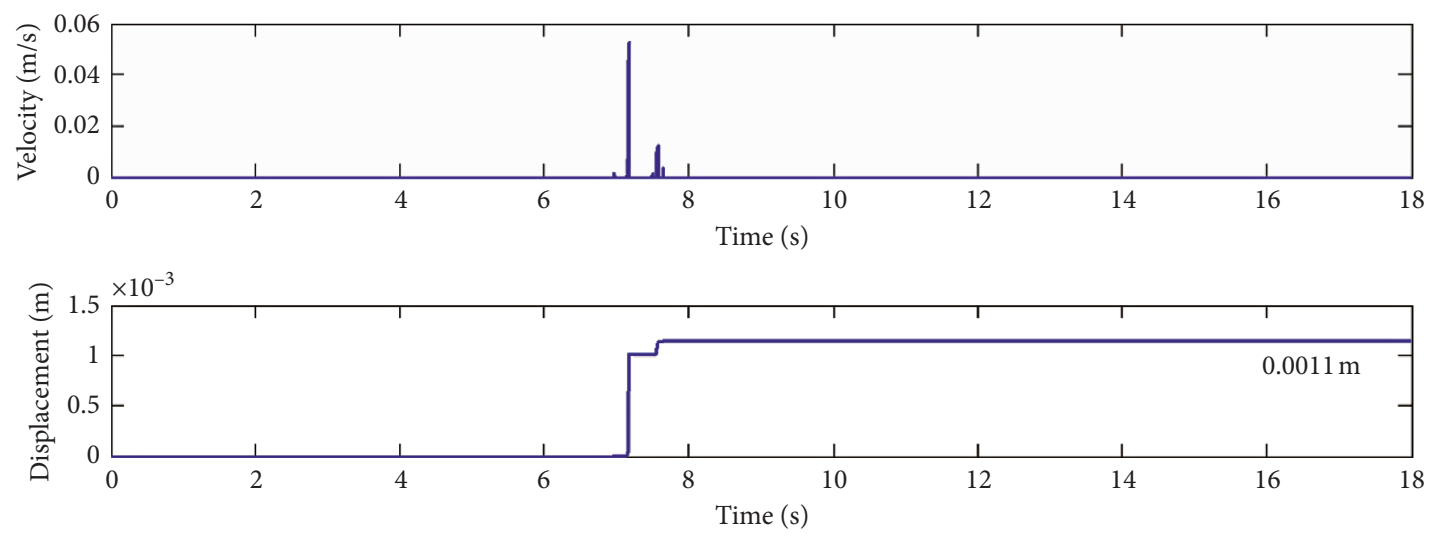

FIgURE 5: Calculation procedure of permanent displacement with the constant critical acceleration.
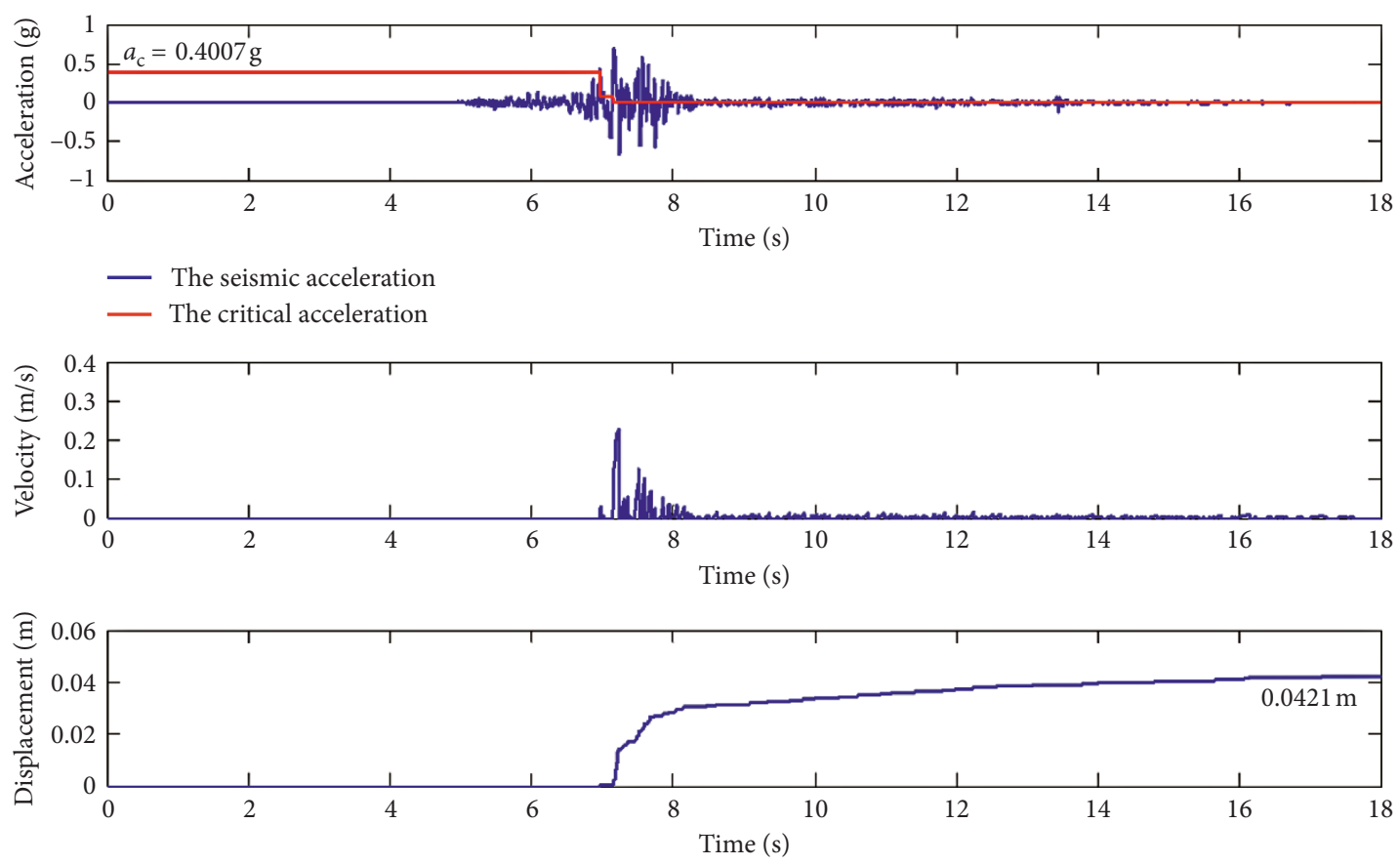

FIgURE 6: Calculation procedure of permanent displacement with the dynamic critical acceleration.

on the bottom of the particles is considered in this method, while the cohesion around the particles themselves is neglected.

The slider thickness represents the depth of potential slide surface, and it is difficult to predict the slide thickness before it slides. Because the mechanism of the deep-seated landslide is complex, it is difficult to calculate this kind of landslide with the Newmark method. Until now, the Newmark method is only used for superficial landslide. Our modified Newmark method is only directed against the shear strength parameters on the slide surface, but without any change to the original physical mode. The possible landslide typology applicable for our modified Newmark method is superficial landslide as usual. 

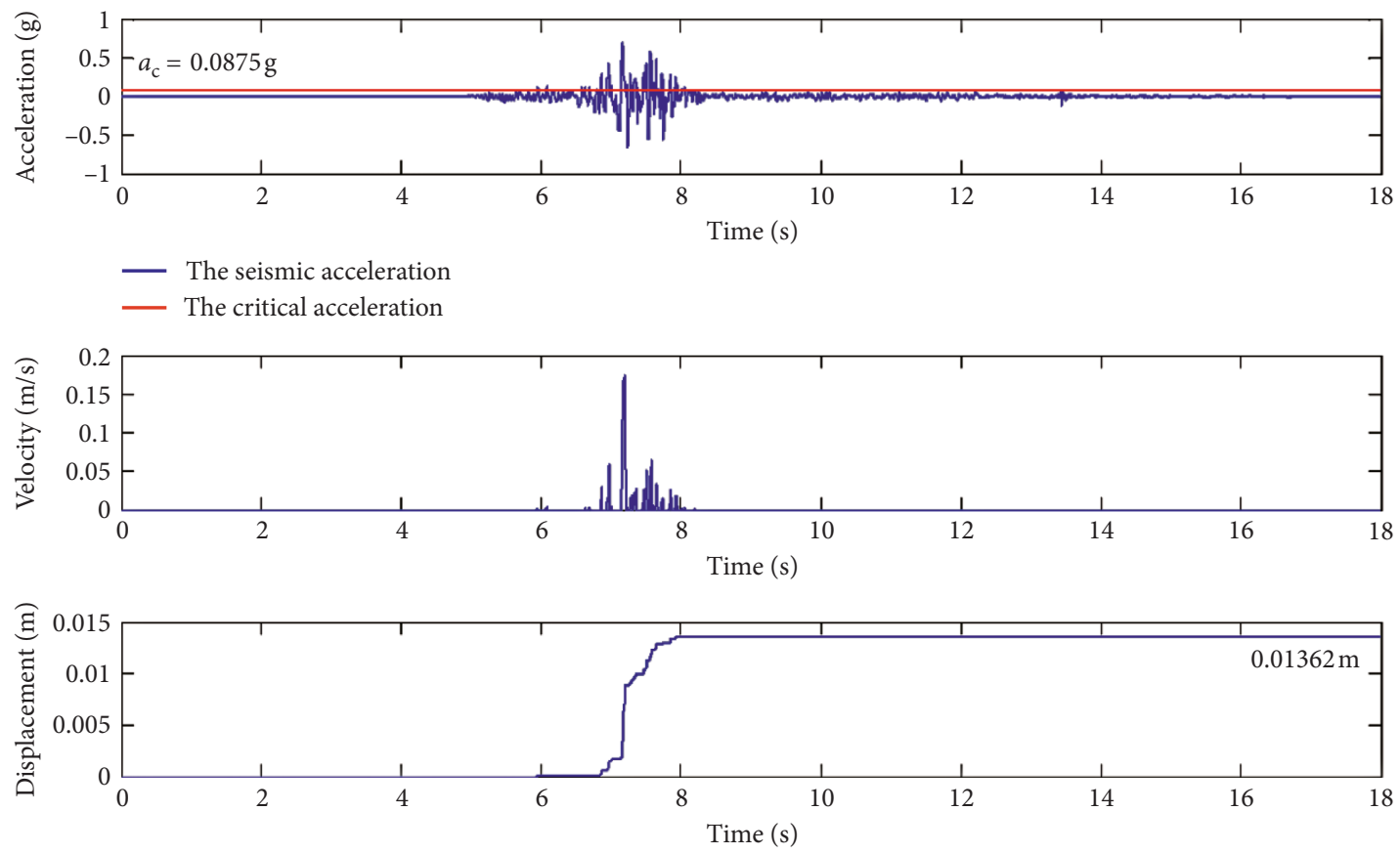

FIgURE 7: Calculation procedure of permanent displacement with a cohesion of 0.

\section{Conclusions}

The assumption that the critical acceleration remains unchanged in the Newmark sliding method can lead to underestimation of the permanent displacement. To solve this problem, this paper proposes an improved approach by virtue of the uneven distribution theory of shear strength of rock-soil bodies. In this modified Newmark method, the disappearance of cohesion on the particles bottom is taken as the judgment condition of the penetration of slide surface. The particles with random cohesion are generated by the Monte Carlo method. Using the MATLAB program, both the cohesion and critical acceleration decreases progressively during the earthquake time history, and then the permanent displacement is obtained. The dropping cohesion and dynamic critical acceleration on the slide bottom is clearly illustrated by a calculation example. The dynamic process of the critical acceleration is corresponded with the earthquake time history. The improved method not only solves the problem that the shear strength change cannot be measured in the earthquake time history, but also overcomes the weakness that the permanent displacement from the Newmark sliding method is smaller than the real displacement.

\section{Data Availability}

The data used to support the findings of this study are included within the article.

\section{Conflicts of Interest}

The authors declare that they have no conflicts of interest.

\section{Acknowledgments}

This research was supported by the National Natural Science Foundation of China (nos. 41807267 and 41661144037) and the Natural Science Research Project of Colleges and Universities in Anhui Province (KJ2018A0075).

\section{References}

[1] F. C. Dai, C. Xu, X. Yao, L. Xu, X. B. Tu, and Q. M. Gong, "Spatial distribution of landslides triggered by the $2008 \mathrm{Ms} 8.0$ Wenchuan earthquake, China," Journal of Asian Earth Sciences, vol. 40, no. 4, pp. 883-895, 2011.

[2] C. Xu, S. Ma, Z. Tan, C. Xie, S. Toda, and X. Huang, "Landslides triggered by the $2016 \mathrm{Mj} 7.3$ Kumamoto, Japan, earthquake," Landslides, vol. 15, no. 3, pp. 551-564, 2018

[3] C. Xu, X. W. Xu, W. J. Zheng et al., "Landslide triggered by the April 20, 2013 Lushan, Sichuan Province M_S7.0 strong earthquake of China," Seismology Geology, vol. 35, no. 3, pp. 641-660, 2013.

[4] K. Chunga, D. Besenzon, M. Mulas et al., "Areal distribution of ground effects induced by the $2016 \mathrm{Mw} 7.8$ Pedernales earthquake (Ecuador)," in Proceedings of the 88 Congresso della Societa'Geologica Italiana, Naples, Italy, September 2016.

[5] T. Ancheta, R. Darragh, J. Stewart et al., "Peer 2013/03-peer Nga-West2 database," in Pacific Earthquake Engineering Research, 2013.

[6] R. Huang, "Mechanism and geomechanical modes of landslide hazards triggered by Wenchuan 8.0 earthquake," Chinese Journal of Rock Mechanics and Engineering, vol. 28, no. 6, pp. 1239-1249, 2009.

[7] M. J. García-Rodríguez, J. A. Malpica, B. Benito, and M. Díaz, "Susceptibility assessment of earthquake-triggered landslides in El Salvador using logistic regression," Geomorphology, vol. 95, no. 3-4, pp. 172-191, 2008. 
[8] P. Lacroix, "Landslides triggered by the Gorkha earthquake in the Langtang valley, volumes and initiation processes," Earth Planets and Space, vol. 68, no. 1, p. 46, 2016.

[9] J. Zhuang, P. Cui, K. Hu, X. Chen, and Y. Ge, "Characteristics of earthquake-triggered landslides and post-earthquake debris flows in Beichuan County," Journal of Mountain Science, vol. 7, no. 3, pp. 246-254, 2010.

[10] N. M. Newmark, "Effects of earthquakes on dams and embankments," Géotechnique, vol. 15, no. 2, pp. 139-160, 1965.

[11] G. F. Wieczorek, R. C. Wilson, and E. L. Harp, "Map showing slope stability during earthquakes in San Mateo County, California," Annals of the New York Academy of Sciences, vol. 681, no. 6431, pp. 64-155, 1985.

[12] S. Wang and J. Zhang, "On the dynamic stability of block sliding on rock slopes," Chinese Journal of Geology, no. 2, pp. 162-170, 1982.

[13] J. Wartman, J. D. Bray, and R. B. Seed, "Inclined plane studies of the Newmark sliding block procedure," Journal of Geotechnical and Geoenvironmental Engineering, vol. 129, no. 8, pp. 673-684, 2003.

[14] S. Xue, S. Wang, and J. Liu, "Analysis of sliding displacements of rockmass on slopes earthquake," Journal of Engineering Geology, vol. 5, no. 2, pp. 131-136, 1997.

[15] H. Liu, "Analysis and computation of sliding wedge in rockmass considered influence of earthguake historical time," Journal of North China Institute of Water Conservancy \& Hydroelectric Power, vol. 4, pp. 35-40, 1991.

[16] S. G. Xiao and G. C. Zhu, "Seismic permanent displacement of clay slopes reinforced with cantilever stabilizing piles," Rock and Soil Mechanics, vol. 34, no. 5, pp. 1345-1359, 2013.

[17] G. X. Xu, L. K. Yao, and C. H. Li, "Energy method for evaluating earthquake induced permanent displacement of soil slopes," Journal of Sichuan University (Engineering Science Edition), vol. 42, no. 5, pp. 285-291, 2010.

[18] K. L. Lu, D. Y. Zhu, Y. L. Zhu et al., "Preliminary study of seismic permanent displacement of 3d slope," Rock and Soil Mechanics, vol. 32, no. 5, pp. 1425-1429, 2011.

[19] S. Huang, B. Song, D. G. Cai et al., "Dynamic response and permanent displacement of high-steep slopes under near-and far-field earthquakes," Chinese Journal of Geotechnical Engineering, vol. 35, no. S2, pp. 768-773, 2013.

[20] M. K. Jafari, K. Amini Hosseini, F. Pellet, M. Boulon, and O. Buzzi, "Evaluation of shear strength of rock joints subjected to cyclic loading," Soil Dynamics and Earthquake Engineering, vol. 23, no. 7, pp. 619-630, 2003.

[21] H. S. Lee, Y. J. Park, T. F. Cho, and K. H. You, "Influence of asperity degradation on the mechanical behavior of rough rock joints under cyclic shear loading," International Journal of Rock Mechanics and Mining Sciences, vol. 38, no. 7, pp. 967-980, 2001.

[22] J. Wartman, R. B. Seed, and J. D. Bray, "Shaking table modeling of seismically induced deformations in slopes," Journal of Geotechnical and Geoenvironmental Engineering, vol. 131, no. 5, pp. 610-622, 2005.

[23] V. Bandini, G. Biondi, E. Cascone, and S. Rampello, "A GLEbased model for seismic displacement analysis of slopes including strength degradation and geometry rearrangement," Soil Dynamics and Earthquake Engineering, vol. 71, pp. 128142, 2015.

[24] H. Li, S. Chi, and G. Lin, "An improved Newmark sliding block method based on stick-slip coupled dynamic response," Chinese Journal of Rock Mechanics and Engineering, vol. 26, no. 9, pp. 1787-1793, 2007.
[25] C. Chen and Y. Xia, "A real-time dynamic Newmark sliding block method for slopes based on limit analysis," Chinese Journal of Rock Mechanics and Engineering, vol. 35, no. 12, pp. 2507-2515, 2016.

[26] T. Crespellani, C. Madiai, and G. Vannucchi, "Earthquake destructiveness potential factor and slope stability," Géotechnique, vol. 48, no. 3, pp. 411-419, 1998.

[27] P. Lumb, "Safety factors and the probability distribution of soil strength," Canadian Geotechnical Journal, vol. 7, no. 3, pp. 225-242, 1970.

[28] C. Luo, K. L. Yin, L. X. Chen et al., "Probability distribution fitting and optimization of shear strength parameters in sliding zone along horizontal-stratum landslides in Wanzhou city," Chinese Journal of Rock Mechanics and Engineering, vol. 24, no. 9, pp. 1588-1593, 2005.

[29] K. Yang, D. S. Liu, Q. Y. Yi et al., "Parameter statistic analysis and application of rock sheering strength in Chongqing," Journal of Logistical Engineering University, vol. 24, no. 2, pp. 18-21, 2008.

[30] M. Gasparini, W. R. Gilks, S. Richardson, and D. J. Spiegelhalter, "Markov chain Monte Carlo in practice," Technometrics, vol. 39, no. 3, p. 338, 1997.

[31] L. H. Chen, Z. Y. Chen, and J. M. Liu, "Probability distribution of soil strength," Rock and Soil Mechanics, vol. 26, no. 1, pp. 37-45, 2005.

[32] C. Liu, S. W. Bai, and H. B. Zhao, "Statistical regularity research of physical and mechanical indexes of clay," Rock and Soil Mechanics, no. S2, pp. 180-184, 2003.

[33] J. Z. Zhang and L. C. Miao, "Types and selection criteria of probability distribution of rock and soil parameters," Chinese Journal of Rock Mechanics and Engineering, vol. 28, no. S2, pp. 3526-3532, 2009.

[34] Y. Gui, S. H. Luo, and T. F. Deng, "Effect of strength parameters statistical property on slope stability reliability," Journal of Civil Architectural and Environmental Engineering, vol. 37, no. 4, pp. 67-76, 2015.

[35] S. G. Cheng, K. H. Fang, and X. Q. Luo, "Probability method to determine shear strength of slide zone clay for neogenic landslide in three Gorges reservoir area," Journal of Rock Mechanics and Engineering, vol. 30, no. S2, pp. 840-845, 2011.

[36] Y. Y. Xia and C. Jiang, "Statistic analysis of shear strength of the slope in Xiang-Lin road in Yunnan Province," Rock and Soil Mechanics, vol. 27, no. 6, pp. 920-924, 2006.

[37] L. H. Yin, X. M. Wang, and L. J. Zhang, "Probabilistical distribution statistical analysis of Tianjin soft soil indices," Rock and Soil Mechanics, no. S2, pp. 462-469, 2010.

[38] D.-Q. Li, S.-H. Jiang, Z.-J. Cao, W. Zhou, C.-B. Zhou, and L.-M. Zhang, "A multiple response-surface method for slope reliability analysis considering spatial variability of soil properties," Engineering Geology, vol. 187, pp. 60-72, 2015.

[39] H. Wang, G. Wang, F. Wang, K. Sassa, and Y. Chen, "Probabilistic modeling of seismically triggered landslides using Monte Carlo simulations," Landslides, vol. 5, no. 4, pp. 387-395, 2008.

[40] C. L. Meehan and F. Vahedifard, "Evaluation of simplified methods for predicting earthquake-induced slope displacements in Earth dams and embankments," Engineering Geology, vol. 152, no. 1, pp. 180-193, 2013. 


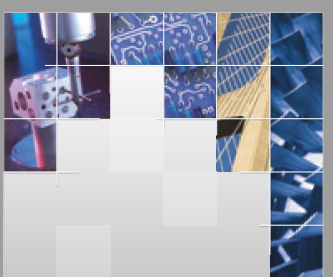

\section{Enfincering}
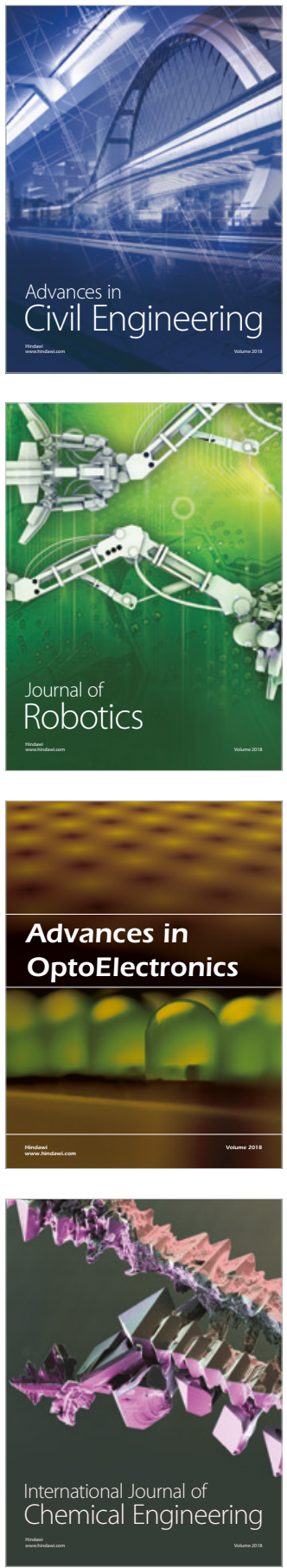

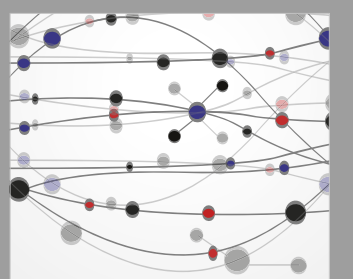

\section{Rotating \\ Machinery}

The Scientific World Journal

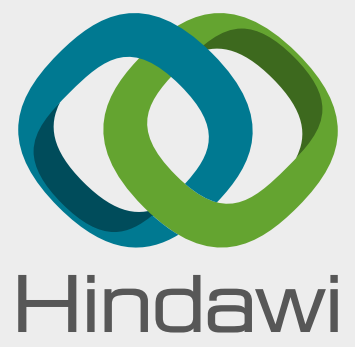

Submit your manuscripts at

www.hindawi.com
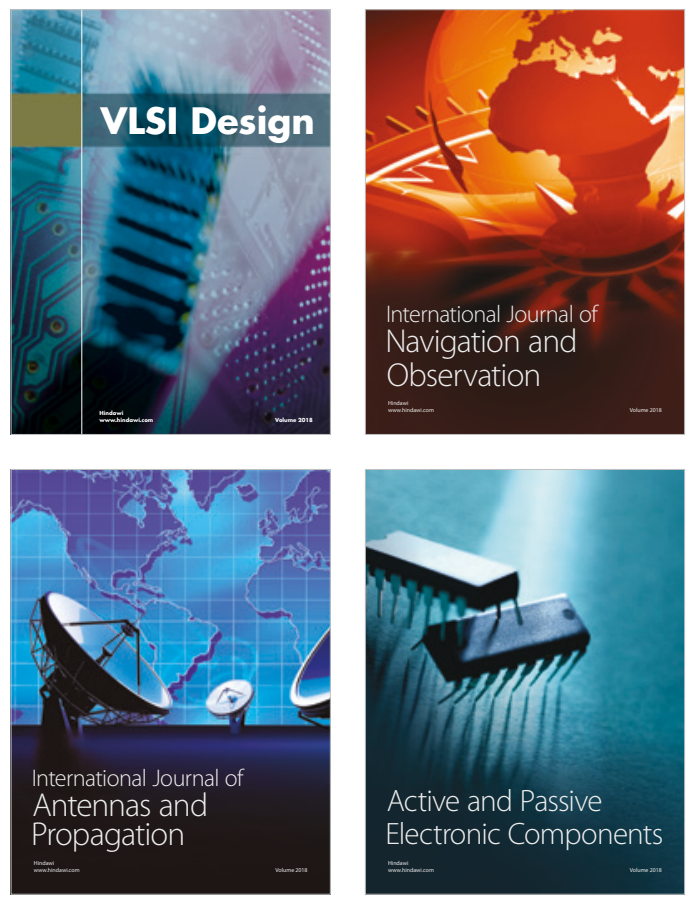
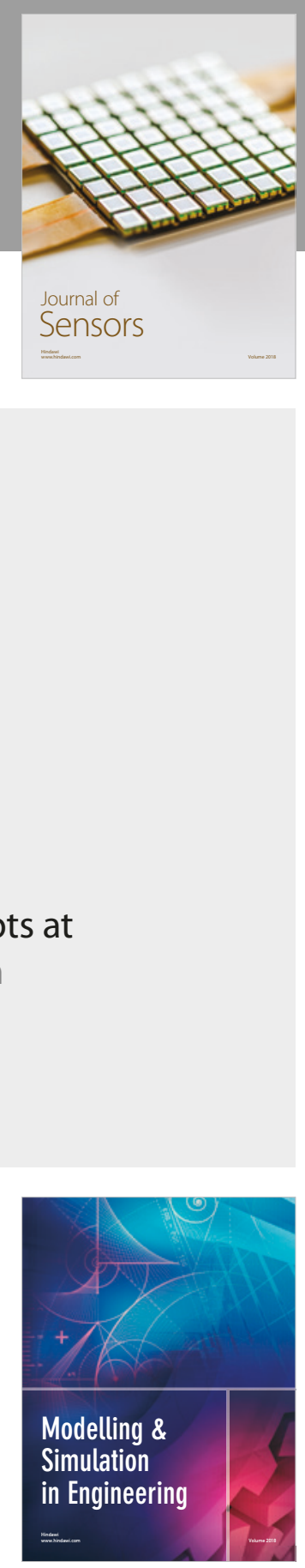

\section{Advances \\ Multimedia}
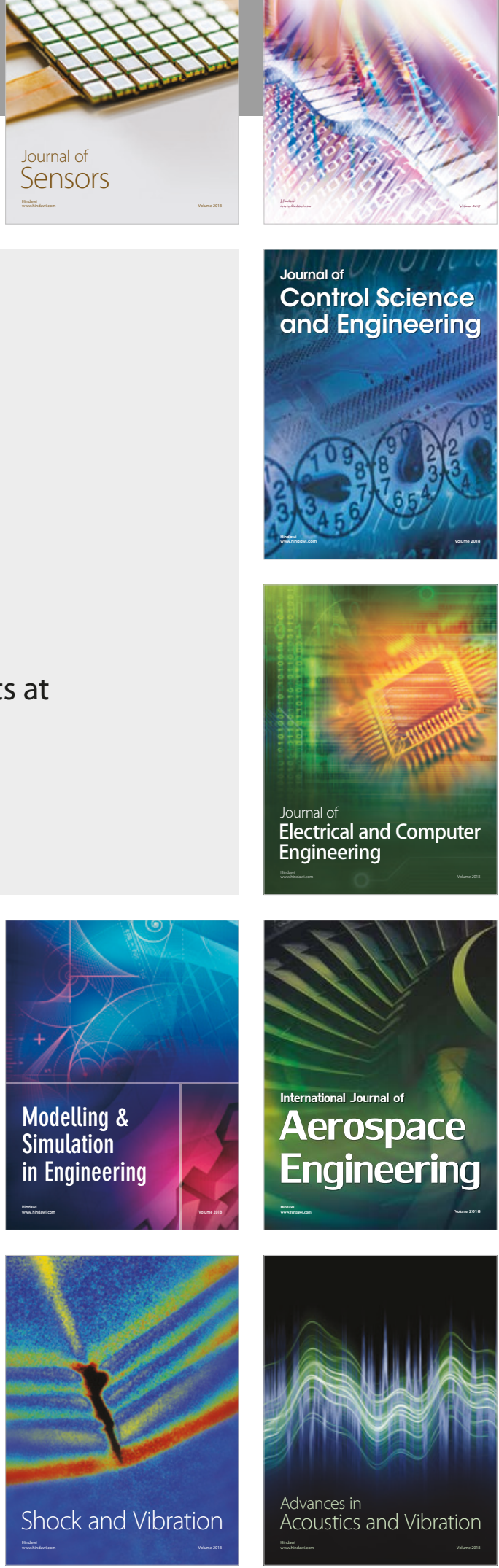